\title{
Sperm counts and sperm sex ratio in male infertility patients
}

\begin{abstract}
Michael L Eisenberg ${ }^{1}$, Lata Murthy ${ }^{2}$, Kathleen Hwang ${ }^{3}$, Dolores J Lamb ${ }^{2}$ and Larry I Lipshultz ${ }^{2}$
In recent years, investigators have noted a trend toward a declining proportion of male births in many industrialized nations. While men bear the sex-determining chromosome, the role of the female partner as it pertains to fertilization or miscarriage may also alter the gender ratio. We attempted to determine a man's secondary sex ratio ( $F 1$ generation) by directly examining the sex chromosomes of his sperm. We examined our male infertility clinic database for all men who had undergone a semen fluorescence in situ hybridization (FISH). Patient demographic and semen parameters were recorded. Chi-squared analysis was used to compare gender ratios (Y chromosomes/total chromosomes). Multivariable logistic regression was used to predict the odds of possessing a Y-bearing sperm after accounting for demographic and semen parameters. A total of 185 men underwent sperm FISH. For the entire cohort, the proportion of $\mathrm{Y}$ chromosome-bearing sperm was $51.5 \%$. Men with less than five million motile sperm had a significantly lower proportion of $Y$ chromosome-bearing sperm (50.8\%) compared to men with higher sperm counts $(51.6 \% ; P=0.02)$. After multivariable adjustment, a higher sperm concentration, total motile sperm count and semen volume significantly increased the odds of having a $Y$

chromosome-bearing sperm $(\boldsymbol{P}<0.01)$. As a man's sperm production declines, so does the proportion of $Y$ chromosome-bearing sperm. Thus, a man's reproductive potential may predict his ability to sire male offspring.

Asian Journal of Andrology (2012) 14, 683-686; doi:10.1038/aja.2012.58; published online 30 July 2012
\end{abstract}

Keywords: infertility; sex ratio; spermatogenesis; sperm chromosomes

\section{INTRODUCTION}

In recent years, a trend toward a declining proportion of male births has been noted in several, but not all, industrialized countries. ${ }^{1-4}$ Indeed, from 1940 until 2002, the proportion of male births has steadily declined in the United States from $51.33 \%$ to $51.17 \% .^{5}$ The etiology of alterations in the sex ratio remains uncertain. Investigators have linked changes in the sex ratio in specific populations to environmental factors or ingested contaminants over discreet time periods. ${ }^{6-11}$

Investigators have postulated both pre- and post-fertilization influences. A Danish group used time to pregnancy as a marker for infertility and found a decline in the offspring gender ratio, hypothesizing that infertile men may have an impaired ability to sire male heirs. ${ }^{12}$ James ${ }^{13}$ reviewed the published literature and examined an additional 2.5 million Australian births and found that the sex ratio appears to decline with time to conception. To explain this phenomenon, investigators have postulated that the more powerful mobility that a $\mathrm{Y}$ chromosome-bearing sperm possesses over its X-bearing counterpart may be diminished, thus lowering the likelihood of a male birth. ${ }^{14,15}$

However, the relationship remains uncertain as a Dutch group found that the proportion of male births increases with time to pregnancy. ${ }^{16}$ In contrast, Jacobsen et al. ${ }^{17}$ found no association between abnormal semen analyses and an altered offspring sex ratio. Moreover, examination of a cohort of infertile couples in California also found no association between the offspring sex ratio and infertility diagnosis, duration or treatment. ${ }^{18}$ In addition, Joffe et al. ${ }^{19}$ examined time to pregnancy and again found no association with sex ratio.

Postfertilization influences on the offspring gender ratio may also be important. Either through genetic defects or maternal rejection, increased proportions of spontaneous abortions of male fetuses may occur. ${ }^{20}$ It has been shown that the sex ratio of a population may change during times of major stressors. ${ }^{8,9,21}$ A common explanation is that male fetuses have a greater likelihood of aborting in the case of stresses to the mother. ${ }^{20,22}$

As female influences are thought to be a powerful mechanism for gender selection, examining a postfertilization and postgestational outcome such as birth may be inadequate to assess the role of the male contribution to the sex ratio. As such, comparing markers of male fertility (i.e., time to pregnancy and semen parameters) to offspring sex ratios may not completely capture the role of the male in determining the sex of the offspring. Therefore, it may be enlightening to examine the relationship between a prefertilization outcome (i.e., sex chromosomes of a man's sperm) and male fertility as assessed by sperm production.

\section{MATERIALS AND METHODS}

Study population

After Institutional Review Board (IRB) at Baylor College of Medicine approval, we examined all men who had undergone evaluation with a sperm fluorescence in situ hybridization (FISH) test. Only men who

${ }^{1}$ Department of Urology, Stanford University School of Medicine, Stanford, CA 94305, USA; ${ }^{2}$ Scott Department of Urology, Baylor College of Medicine, Houston, TX 77030, USA and ${ }^{3}$ Department of Urology, Brown University, Providence, RI 02912, USA

Correspondence: Dr ML Eisenberg (eisenberg@stanford.edu)

Received: 12 March 2012; Revised: 9 April 2012; Accepted: 16 May 2012; Published online: 30 July 2012 
were able to produce an ejaculated sperm sample were eligible for testing. Men from couples with recurrent pregnancy loss $(\geqslant 2$ pregnancy losses), in vitro fertilization failure ( $\geqslant 2$ failed in vitro fertilization (IVF) cycles) or unexplained infertility (normal female and male fertility evaluation in couples who were unable to conceive after 1 year of unprotected intercourse) were offered sperm FISH testing. Patient age, year of evaluation, reason for sperm FISH, proportion of sperm aneuploidy, semen volume, sperm concentration and sperm motility were recorded. In addition, the numbers of X- and Y-bearing sperm were determined.

\section{Semen analysis and sperm FISH analysis}

Semen analysis was performed within 60 min of collection using a manual counting technique with a hemacytometer under $\times 400$ magnification. The volume, concentration (million per $\mathrm{ml}$ ) and motility were recorded. Volume, percent motility and concentration were multiplied to determine the total motile sperm count (TMC= volume $\times$ concentration $\times$ motility).

The rationale and methods of semen analysis and sperm FISH analysis have been previously described. ${ }^{23,24}$ Briefly, sperm was first fixed to glass slides. Five-color FISH was then used to detect chromosomes $\mathrm{X}, \mathrm{Y}, 13,18$ and 21 using direct-labeled chromosome-specific probes.

\section{Statistical analysis}

The median value for each parameter of a semen analysis (volume, concentration, motility and TMC) was calculated. Next, the population was stratified as either above or below the median value for volume, concentration, motility and TMC. The gender ratio (Y chromosome-bearing sperm/total sperm analyzed) for each category was determined and chi-squared analysis was performed for compared groups.

After the total motile sperm count was calculated, the population was stratified based on TMC cutoffs of 1, 5, 10, 20 or 45 million. The sex ratio ( $\mathrm{Y}$ chromosome-bearing sperm/total sperm analyzed) for each TMC category was determined and chi-squared analysis was performed for compared groups.

An analysis on a per sperm basis was performed by assigning the relevant semen parameter for each sperm analyzed. Logistic regression was used to determine the relationship between the seminal parameters (volume, concentration, motility and TMC) and the odds of producing a Y chromosome-bearing sperm ( $v s$. X chromosome-bearing sperm) after accounting for age, time of evaluation, days of abstinence and overall aneuploidy of the semen sample. Given that a high aneuploidy rate observed in sperm may impact the proportion of $\mathrm{Y}$ chromosome-bearing sperm, aneuploidy was included in our model. Removal of this factor did not measurably impact any measures of association nor alter the conclusions. Odds ratios were generated after transforming all semen analysis characteristics $\times 100$ to facilitate reporting of the measures of association. Statistical significance was set at $P<0.05$. All $P$ values are two-sided. Analyses were performed using Stata 10 (StataCorp LP, College Station, TX, USA).

\section{RESULTS}

In all, 185 men underwent a sperm FISH from 2003 to 2010 with a mean age (s.d.) of 37.9 (6.4) years. During those years, approximately 2100 men were evaluated for infertility in our Division of Male Reproductive Medicine and Surgery. Thus, the current cohort represents approximately $9 \%$ of all infertile men evaluated. Most men for whom data were available underwent testing for IVF failure (55\%). An average of 669.5 sperm were evaluated per man. The mean semen volume was $2.9 \mathrm{ml}$, and the mean sperm concentration was 48.8 million per ml with a mean motility of $47.2 \%$. The average total motile sperm count was 76.7 million with $42(23.0 \%)$ men having less than five million total motile sperm in their ejaculate (Table 1).

The overall sperm Y/X ratio for the cohort was 51.4: 48.6. Men with a semen volume or sperm concentration below the median had a lower proportion of Y-bearing sperm (Table 2). After stratifying by TMC, men with $<1,5,10$ and 20 million motile sperm had a significantly reduced proportion of Y-bearing spermatozoa compared to those with higher sperm production (Table 3; $P<0.05$ ). When the TMC cut point reached 45 million, there was no significant difference in the percentage of $\mathrm{X}$ - and $\mathrm{Y}$-bearing sperm between men with more or less than the cutoff $(P=0.11)$.

On age-adjusted models, there was a positive relationship between the odds of producing a $\mathrm{Y}$ chromosome-bearing sperm and semen volume as well as TMC (Table 4). After adjusting for age, date of FISH study, days of abstinence and degree of aneuploidy of sperm sample, a positive relationship existed with volume, concentration and TMC $(P<0.01)$. No relationship existed between the proportion of $\mathrm{Y}$ bearing spermatozoa and sperm motility.

\section{DISCUSSION}

The current study shows an inverse relationship between the production of Y chromosome-bearing sperm and sperm production among the infertile men, suggesting an impaired ability for infertile men to sire male heirs. TMC, sperm concentration and semen volume all showed a positive relationship with the proportion of Y-bearing sperm.

Other groups have examined whether infertility impacts the offspring gender ratio. Joffe et al. ${ }^{19}$ examined data from four European datasets ( $n=49506$ births) and found no relationship between time to

\section{Table 1 Characteristics of sperm FISH patients}

\begin{tabular}{|c|c|c|}
\hline Characteristic & & Value \\
\hline Patient number & & 185 \\
\hline Patient age (mean \pm s.d.), year & & $37.9 \pm 6.4$ \\
\hline \multirow{6}{*}{$\begin{array}{l}\text { Patient age, year } \\
\text { categories, } n(\%)\end{array}$} & $<30$ & $9(5)$ \\
\hline & $30-35$ & $46(25)$ \\
\hline & $35-40$ & $68(38)$ \\
\hline & $40-45$ & $29(16)$ \\
\hline & $45-50$ & $15(8)$ \\
\hline & $>50$ & $14(8)$ \\
\hline \multirow[t]{4}{*}{ Period of evaluation, $n(\%)$} & 2003-2004 & $47(26)$ \\
\hline & 2005-2006 & $71(39)$ \\
\hline & 2007-2010 & 34 (19) \\
\hline & 2009-2010 & $28(16)$ \\
\hline \multirow{4}{*}{$\begin{array}{l}\text { Reasons for sperm } \\
\text { FISH testing, } n(\%)\end{array}$} & IVF failure & $21(55)$ \\
\hline & Recurrent miscarriage & $2(5)$ \\
\hline & IUI failure & $8(21)$ \\
\hline & Unexplained infertility & $7(18)$ \\
\hline $\begin{array}{l}\text { Previous paternity at the } \\
\text { time of infertility evaluation }\end{array}$ & & $0 / 38$ \\
\hline \multirow{5}{*}{$\begin{array}{l}\text { Semen analyses, } \\
\text { mean } \pm \text { s.d. (median) }\end{array}$} & Days abstinent & $3.7 \pm 2.5(3)$ \\
\hline & Volume (ml) & $2.9 \pm 1.6(2.5)$ \\
\hline & $\begin{array}{l}\text { Concentration } \\
\text { (million per ml) }\end{array}$ & $48.8 \pm 48.2(34)$ \\
\hline & Motility (\%) & $47.2 \pm 21.9(50)$ \\
\hline & TMC (million) & $76.7 \pm 83.7$ (51.3) \\
\hline $\begin{array}{l}\text { Average sperm } \\
\text { evaluated per man }\end{array}$ & & $669.5 \pm 254.9$ \\
\hline
\end{tabular}

Abbreviations: FISH, fluoroescence in situ hybridization; IUI, intrauterine insemination; IVF, in vitro fertilization; TMC, total motile sperm count. 
Table 2 The proportions of Y-bearing sperm are listed after stratifying by the median values for semen volume, sperm concentration, sperm motility and TMC

\begin{tabular}{|c|c|c|c|c|c|}
\hline Semen characteristics (Median cutoff) & $\mathrm{n}$ & $T M C$ (mean $\pm s . d)$. & Total sperm & Ysperm (\%) & $\mathrm{P}^{*}$ \\
\hline \multicolumn{6}{|l|}{ Volume } \\
\hline$\leqslant 2.5 \mathrm{ml}$ & 95 & $1.7 \pm 0.6$ & 61332 & 50.9 & \multirow[t]{2}{*}{$<0.01$} \\
\hline$>2.5 \mathrm{ml}$ & 90 & $4.2 \pm 1.5$ & 59176 & 52.1 & \\
\hline \multicolumn{6}{|l|}{ Concentration } \\
\hline$\leqslant 34$ millions per $\mathrm{ml}$ & 93 & $13.6 \pm 11.6$ & 60143 & 51.2 & \multirow[t]{2}{*}{0.05} \\
\hline >34 millions per ml & 90 & $85.2 \pm 44.4$ & 58456 & 51.7 & \\
\hline \multicolumn{6}{|l|}{ Motility } \\
\hline$\leqslant 50 \%$ & 94 & $29.7 \pm 15.8$ & 60496 & 51.4 & \multirow[t]{2}{*}{0.82} \\
\hline$>50 \%$ & 89 & $65.7 \pm 7.5$ & 58103 & 51.5 & \\
\hline \multicolumn{6}{|l|}{ TMC } \\
\hline$\leqslant 51.3 \times 10^{6}$ & 92 & $13.5 \pm 15.5$ & 60548 & 51.3 & \multirow[t]{2}{*}{0.28} \\
\hline$>51.3 \times 10^{6}$ & 91 & $140.5 \pm 75.6$ & 58051 & 51.6 & \\
\hline
\end{tabular}

Abbreviation: TMC, total motile sperm count.

$* P$ value represents chi-squared test.

pregnancy and gender ratio. In the analysis, couples with $>1$ year of time to pregnancy were labeled infertile, but the specific infertility factors could not be assessed. In all the analyzed datasets, live births were assessed, but the individual parental contributions could not be separated. Examination of a US cohort ( $n=15309$ births) also failed to demonstrate any difference in offspring sex ratio between fertile and infertile couples. ${ }^{18}$ Jacobsen et al. ${ }^{17}$ linked semen data from men analyzed at the Sperm Analysis Laboratory in Copenhagen, Denmark over a 30-year period with birth registry data to determine if the offspring sex ratio varied based on semen parameters. The authors examined 25738 births and found no association between semen characteristics and sex ratio, suggesting that there was no association between a man's sperm production and the offspring sex ratio.

Yet other groups have found a relationship between time to pregnancy and sex ratio. Smits et al. ${ }^{16}$ queried 5283 women and found that a longer time to pregnancy was positively associated with the proportion of male births. In contrast, Zhou et al. ${ }^{12}$ examined data from the 'Healthy Habits for two' study conducted in two Danish cites and noted a decline in the offspring gender ratio for couples (10 042 births) with a longer time to pregnancy ( $>12$ months). James ${ }^{13}$ examined approximately 2.5 million Australian births and also found that the sex ratio appears to decline with time to conception. Using offspring number as a surrogate for fertility, Edwards ${ }^{25}$ reported a positive correlation between offspring number and the offspring sex ratio using German birth data from the nineteenth century.

Table 3 The proportions of X- and Y-bearing sperm are listed after stratifying by the total motile sperm count (TMC)

\begin{tabular}{lrcccc}
\hline $\begin{array}{l}\text { TMC category } \\
\text { (millions) }\end{array}$ & $\mathrm{n}$ & $\begin{array}{l}\text { TMC } \\
\text { (mean } \pm \text { s.d.) }\end{array}$ & $\begin{array}{l}\text { Total } \\
\text { sperm }\end{array}$ & Ysperm (\%) & $\mathrm{P}^{*}$ \\
\hline$<1$ & 21 & $0.4 \pm 0.3$ & 9567 & 50.4 & 0.03 \\
$\geqslant 1$ & 162 & $89.1 \pm 83.4$ & 109032 & 51.5 & \\
$<5$ & 42 & $1.6 \pm 1.4$ & 21958 & 50.8 & 0.02 \\
$\geqslant 5$ & 141 & $100.2 \pm 82.2$ & 96641 & 51.6 & \\
$<10$ & 55 & $3.3 \pm 3.0$ & 88217 & 50.9 & 0.04 \\
$\geqslant 10$ & 128 & $109.0 \pm 80.7$ & 30382 & 51.6 & \\
$<20$ & 67 & $5.5 \pm 5.3$ & 37562 & 51.0 & 0.04 \\
$\geqslant 20$ & 116 & $117.4 \pm 78.9$ & 81037 & 51.7 & \\
$<45$ & 86 & $12.5 \pm 13.1$ & 50952 & 51.2 & 0.11 \\
$\geqslant 45$ & 97 & $134.3 \pm 75.7$ & 67647 & 51.6 & \\
\hline
\end{tabular}

* $P$ value represents chi-squared test.
The reason for different findings of the studies, including the current report, is unclear. Admittedly, any changes in sex ratio are likely to be small. Certainly, larger datasets will have more power to detect small differences in sex ratio which may explain some of the observed differences. In addition, population-based offspring samples may be misleading due to individual choices that couples have made about family size based on offspring gender. Moreover, using timing of conception as it relates to marriage or the number of offspring may be imprecise surrogates for fertility potential. ${ }^{13,25}$ It may also be that examining the fertility potential of each member of a couple (i.e., male factor $v$ s. female factor) may be important rather than examining fertility at the level of the couple.

In addition, given that societal stresses may impact sex ratio through unclear mechanisms, examining the sex chromosome composition of the gamete may be more enlightening for determining the parental contribution than looking at the sex of the resultant offspring. ${ }^{8,9,21}$. In fact, it is conceivable that societal stresses may first impact sperm quality which may in turn then affect sex ratio as suggested by Fukada and colleagues ${ }^{9,26}$ who noted both a decline in sperm motility and sex ratio after the Kobe earthquake. It is important to note that while Robbins et al. ${ }^{27}$ suggest that the proportion of Ybearing sperm is related to the offspring sex ratio, to our knowledge, no studies have directly measured a relationship.

The current report suggests that men with impaired spermatogenesis have a diminished capacity to produce Y-bearing sperm and possibly male heirs. This supports the hypothesis that a common biological factor may act upon the male reproductive system and

Table 4 Logistic regression models to estimate the odds of Y-bearing sperm $^{\mathrm{a}}$

\begin{tabular}{lcrlcrr}
\hline \multirow{2}{*}{$\begin{array}{l}\text { Semen } \\
\text { characteristics }\end{array}$} & \multicolumn{2}{c}{ Age adjusted } & & \multicolumn{2}{c}{ Fully adjusted $^{\mathrm{b}}$} \\
\cline { 2 - 3 } & OR $(95 \% \mathrm{Cl})$ & $\mathrm{P}$ & & OR $(95 \% \mathrm{Cl})$ & $\mathrm{P}$ \\
\hline Volume & $5.14(2.55-10.36)$ & $<0.01$ & & $3.65(1.59-8.38)$ & $<0.01$ \\
Concentration & $1.02(1.00-1.05)$ & 0.08 & & $1.05(1.01-1.08)$ & $<0.01$ \\
Motility & $1.04(0.98-1.10)$ & 0.20 & & $1.02(0.95-1.10)$ & 0.56 \\
TMC & $1.02(1.01-1.03)$ & $<0.01$ & & $1.03(1.01-1.05)$ & $<0.01$ \\
\hline
\end{tabular}

Abbreviations: $\mathrm{Cl}$, confidence interval; OR, odds ratio; TMC, total motile sperm count.

a Odds ratios were generated after transforming all semen analysis characteristics $\times 100$ to facilitate reporting.

${ }^{\mathrm{b}}$ Adjusted for age, date of analysis, days of abstinence and aneuploidy of sample. 
impair fertility and the offspring sex ratio. ${ }^{28,29}$ Moreover, the current findings support the hypothesis which suggests that natural selection should favor parental ability to adjust the sex ratio of offspring according to the reproductive fitness of the parents. ${ }^{30}$ Thus, men with impaired semen production should sire less male offspring who risk similar hardships with reproduction. Instead, subfertile men should sire daughters whose own reproductive success would be unlikely to be impaired from a paternal spermatogenic deficit.

Certain limitations warrant mention. While over 119000 sperm were analyzed, the number of individual men for evaluation was limited. In addition, despite our criteria for sperm FISH being fairly stringent, many couples who were offered the test either refused or were unable to afford the study. Due to the possible biases in cohort assembly, it is possible that the results occurred by chance alone. Moreover, as most couples who obtained sperm FISH had IVF failure, it is uncertain if the findings are applicable to all men and further confirmatory studies are warranted. Nevertheless, our study represents an examination of the man's isolated contribution to offspring sex and suggests a relationship between sperm production and the sex chromosome composition of sperm.

\section{AUTHOR CONTRIBUTIONS}

MLE and LIL conceived the project. LM, KH and DJL performed FISH preparation, analysis and interpretation. MLE analyzed the data and MLE drafted the manuscript. All authors provided critical revisions for the manuscript.

\section{COMPETING FINANCIAL INTERESTS}

The authors declare no conflict of interest.

Davis DL, Gottlieb MB, Stampnitzky JR. Reduced ratio of male to female births in several industrial countries: a sentinel health indicator? JAMA 1998; 279: 1018-23.

2 Moller $\mathrm{H}$. Change in male:female ratio among newborn infants in Denmark. Lancet 1996; 348: 828-9.

3 Astolfi P, Zonta LA. Reduced male births in major Italian cities. Hum Reprod 1999; 14: 3116-9.

4 Parazzini F, La Vecchia C, Levi F, Franceschi S. Trends in male:female ratio among newborn infants in 29 countries from five continents. Hum Reprod 1998; 13: 1394-6.

5 Mathews TJ, Hamilton BE. Trend analysis of the sex ratio at birth in the United States. Natl Vital Stat Rep 2005; 53: 1-17.
6 Goldsmith JR, Potashnik G, Israeli R. Reproductive outcomes in families of DBCPexposed men. Arch Environ Health 1984; 39: 85-9.

7 Wyatt R, Wilson AM. Children of anaesthetists. Br Med J 1973; 1: 675.

8 Zorn B, Sucur V, Stare J, Meden-Vrtovec H. Decline in sex ratio at birth after 10-day war in Slovenia: brief communication. Hum Reprod 2002; 17: 3173-7.

9 Fukuda M, Fukuda K, Shimizu T, Moller H. Decline in sex ratio at birth after Kobe earthquake. Hum Reprod 1998; 13: 2321-2.

10 Baste V, Riise T, Moen BE. Radiofrequency electromagnetic fields; male infertility and sex ratio of offspring. Eur J Epidemiol 2008; 23: 369-77.

11 James WH. Offspring sex ratio as an indicator of reproductive hazards associated with pesticides. Occup Environ Med 1995; 52: 429-30.

12 Zhou WJ, Olsen J. Offspring sex ratio as an indicator of reproductive hazards. Occup Environ Med 1996; 53: 503-4

13 James WH. The variations of human sex ratio at birth with time of conception within the cycle, coital rate around the time of conception, duration of time taken to achieve conception, and duration of gestation: a synthesis. J Theor Biol2008; 255: 199-204.

14 Ericsson RJ, Langevin CN, Nishino M. Isolation of fractions rich in human Y sperm. Nature 1973; 246: 421-4.

15 Pyrzak R. Separation of X- and Y-bearing human spermatozoa using albumin gradients. Hum Reprod 1994; 9: 1788-90.

16 Smits LJ, de Bie RA, Essed GG, van den Brandt PA. Time to pregnancy and sex of offspring: cohort study. BMJ 2005; 331: 1437-8.

17 Jacobsen R, Bostofte E, Skakkebaek NE, Hansen J, Moller H. Offspring sex ratio of subfertile men and men with abnormal sperm characteristics. Hum Reprod 2000; 15: 2369-70.

18 Eisenberg ML, Schembri M, Croughan MS, Walsh TJ. Fecundity and sex ratio of offspring in an infertile cohort. Fertil Steril 2011; 96: 833-6.

19 Joffe M, Bennett J, Best N, Jensen TK. Sex ratio and time to pregnancy: analysis of four large European population surveys. BMJ 2007; 334: 524.

20 Catalano R, Bruckner T, Anderson E, Gould JB. Fetal death sex ratios: a test of the economic stress hypothesis. Int J Epidemiol 2005; 34: 944-8.

21 Catalano RA. Sex ratios in the two Germanies: a test of the economic stress hypothesis. Hum Reprod 2003; 18: 1972-5.

22 Owen D, Matthews SG. Glucocorticoids and sex-dependent development of brain glucocorticoid and mineralocorticoid receptors. Endocrinology2003; 144: 2775-84.

23 Ryu HM, Lin WW, Lamb DJ, Chuang W, Lipshultz LI et al. Increased chromosome X, Y, and 18 nondisjunction in sperm from infertile patients that were identified as normal by strict morphology: implication for intracytoplasmic sperm injection. Fertil Steril 2001; 76: 879-83

24 Harton GL, Tempest HG. Chromosomal disorders and male infertility. Asian J Androl 2012; 14: 32-9.

25 Edwards AW. An analysis of Geissler's data on the human sex ratio. Ann Hum Genet 1958; 23: 6-15.

26 Fukuda M, Fukuda K, Shimizu T, Yomura W, Shimizu S. Kobe earthquake and reduced sperm motility. Hum Reprod 1996; 11: 1244-6.

27 Robbins WA, Wei F, Elashoff DA, Wu G, Xun L et al. Y:X sperm ratio in boron-exposed men. J Androl 2008; 29: 115-21.

28 Skakkebaek NE, Rajpert-De Meyts E, Main KM. Testicular dysgenesis syndrome: an increasingly common developmental disorder with environmental aspects. Hum Reprod 2001; 16: 972-8.

29 Jacobsen R, Bostofte E, Engholm G, Hansen J, Skakkebaek NE et al. Fertility and offspring sex ratio of men who develop testicular cancer: a record linkage study. Hum Reprod 2000; 15: 1958-61.

30 Trivers RL, Willard DE. Natural selection of parental ability to vary the sex ratio of offspring. Science 1973; 179: 90-2. 